\title{
Direct inversion of circulation from tracer measurements - Part 2: Sensitivity studies and model recovery tests
}

\author{
Thomas von Clarmann and Udo Grabowski \\ Institute of Meteorology and Climate Research, Karlsruhe Institute of Technology, Karlsruhe, Germany
}

Correspondence: Thomas von Clarmann (thomas.clarmann@kit.edu)

Received: 23 January 2020 - Discussion started: 16 March 2020

Revised: 4 December 2020 - Accepted: 4 January 2021 - Published: 19 February 2021

\begin{abstract}
The direct inversion of the 2D continuity equation allows for the inference of the effective meridional transport of trace gases in the middle stratosphere. This method exploits the information given by both the displacement of patterns in measured trace gas distributions and the approximate balance between sinks and horizontal as well as vertical advection. Model recovery tests show that with the current setup of the algorithm, this method reliably reproduces the circulation patterns in the entire analysis domain from 6 to $66 \mathrm{~km}$ altitude. Due to the regularization of the inversion, velocities above about $30 \mathrm{~km}$ are more likely under- than overestimated. This is explained by the fact that the measured trace gas distributions at higher altitudes generally contain less information and that the regularization of the inversion pushes results towards 0 . Weaker regularization would in some cases allow a more accurate recovery of the velocity fields, but there is a price to pay in that the risk of convergence failure increases. No instance was found where the algorithm generated artificial patterns not present in the reference fields. Most information on effective velocities above $50 \mathrm{~km}$ is included in measurements of $\mathrm{CH}_{4}, \mathrm{CO}, \mathrm{H}_{2} \mathrm{O}$, and $\mathrm{N}_{2} \mathrm{O}$, while CFC-11, HCFC-22, and CFC-12 constrain the inversion most efficiently in the middle stratosphere. $\mathrm{H}_{2} \mathrm{O}$ is a particularly important tracer in the upper troposphere or lower stratosphere. $\mathrm{SF}_{6}$ and $\mathrm{CCl}_{4}$ generally contain less information but still contribute to the reduction in the estimated uncertainties. With these tests, the reliability of the method has been established.
\end{abstract}

\section{Introduction}

Traditionally, the observational analysis of the strength of the Brewer-Dobson circulation relies on the concept of the mean age of stratospheric air (AoA; Waugh and Hall, 2002). The AoA is the average transport time of an air parcel from the stratospheric entry point to the measurement location and is estimated from the mixing ratio of an age tracer such as $\mathrm{SF}_{6}$. An alternative method, suggested by von Clarmann and Grabowski (2016, henceforth abbreviated vCG16), derives meridional circulation fields from two subsequent sets of global zonal mean vertically resolved pressure: temperature and mixing ratios of multiple long-lived trace gases by direct inversion of the continuity equation. This method is called Analysis of the Circulation of the Stratosphere Using Spectroscopic Measurements (ANCISTRUS). The resulting quantities are effective $2 \mathrm{D}$ velocities, that is to say, those $2 \mathrm{D}$ velocities which best describe the observed temporal changes in air density and constituent mixing ratio distributions by transport. They thus include all effects caused by longitudinal or temporal correlations between mixing ratios and velocities. The relationship of these effective $2 \mathrm{D}$ velocities to $3 \mathrm{D}$ velocities is discussed in the appendices of vCG16 and von Clarmann et al. (2019, henceforth vC19). Beyond this, the ANCISTRUS-derived effective velocities currently also include a contribution by physical mixing and thus are not directly comparable to the $2 \mathrm{D}$ residual circulation in the transformed Eulerian mean framework.

Similar to in other applications of inverse modeling, such as retrieval of atmospheric state variables from radiance measurements (e.g., Rodgers, 2000) or data assimilation (e.g., Ide et al., 1997), each iteration of the inversion scheme in ANCISTRUS consists of two steps: a forward modeling step and the inversion itself. In the forward modeling step, the current 
guess of the effective velocity field is applied to an initial field of measured atmospheric state variables (air density and mixing ratios of species) to solve the predictive version of the continuity equation. Sinks of trace gases due to photolysis, $\mathrm{OH}$ chemistry and $\mathrm{O}^{1} \mathrm{D}$ chemistry are taken into account following the approach described in vC19. Along with this, the partial derivatives of each atmospheric state variable with respect to each element of the velocity vector are calculated. In the inverse step, the predicted field of the atmospheric state variables is compared with its measured counterpart, and the weighted residual is minimized by inverting the continuity equation. The weights are represented by the inverse covariance matrix, including measurement uncertainties and prediction errors. To keep the inversion stable, a constraint is applied.

The natural application of this method is the analysis of the Brewer-Dobson circulation (Brewer, 1949; Dobson, 1956). ANCISTRUS avoids certain drawbacks of the hitherto common method using the mean age of stratospheric air (Waugh and Hall, 2002) as a diagnostic of the circulation. No age spectra (Andrews et al., 1999; Waugh and Hall, 2002) have to be assumed. Intrusion of mesospheric $\mathrm{SF}_{6}$-depleted air does not cause artificial "overaging" of the air (Stiller et al., 2012; Reddmann et al., 2001; Ray et al., 2017) because for gases without a stratospheric sink, ANCISTRUS takes all information from mixing ratio differences within the analysis domain and not from the absolute abundances. Age-of-airbased methods exploit the measured mixing ratio difference between the stratospheric entry point and the measurement location, and the air might have been depleted in $\mathrm{SF}_{6}$ during its potential detour through the mesosphere. The mesospheric loss of $\mathrm{SF}_{6}$ increases the difference and makes the air appear older than it actually is. In contrast, ANCISTRUS exploits the measured difference in the mixing ratios of $\mathrm{SF}_{6}$ between the endpoint and the starting point of a path element of the trajectory only in the domain considered. If the air parcel has re-entered the analysis domain after a possible detour through the mesosphere, any mesospheric loss has affected both the starting point and the endpoint of the path element and thus does not contribute to the difference. And finally, the method does not provide the integrated travel time of an air parcel only but provides time-resolved results.

Applying ANCISTRUS to trace gas mixing ratios measured with the Michelson Interferometer for Passive Atmospheric Sounding (MIPAS; Fischer et al., 2008) results in circulation fields that include the expected features like tropical uplift, polar winter subsidence, stratospheric poleward transport, mesospheric pole-to-pole circulation, and elevated stratopauses (vC19). Furthermore, results proved to be stable in the sense that for each year - within the expected range of variability - similar circulation fields were found for any particular time of the year, although the estimates were independent from each other. The ANCISTRUS version used in this paper includes several updates with respect to the original method by vCG16. In particular, sinks of trace gases are considered and mixing coefficients are constrained to 0 . The latter implies that resulting velocities are effective velocities that also account for the effect of eddy mixing and physical diffusion. Further details are reported in vC19. Application to trace gas distributions obtained from other satellite missions, such as the Microwave Limb Sounder (MLS; Waters et al., 2006) or the Atmospheric Chemistry Experiment - Fourier Transform Spectrometer (ACE-FTS; Bernath et al., 2005) is under consideration.

Since chemical decomposition has been newly implemented in the most recent ANCISTRUS version, the effect of the consideration of sinks is investigated in Sect. 2. The purpose of this investigation is to find out how much information on the circulation is provided by the sinks and how much is provided by the displacement of mixing ratio patterns. In order to further increase the confidence in the new inversionbased method, in this paper we validate the inverse method by model recovery tests. For these tests, mixing ratio distributions are modeled using known effective velocities. These mixing ratio distributions are then fed into ANCISTRUS to test how well the initial velocity field is recovered (Sect. 3).

These tests are complemented by an assessment of the dependence of the results on the regularization strength (Sect. 4). Further, we study the sensitivity of the model to the availability of various trace gas fields (Sect. 5). In the Conclusions (Sect. 6) we discuss the power and the limitations of the method as discovered in this work and make suggestions for further work.

\section{Sinks versus transported structures}

Two mechanisms link mixing ratio distributions with the circulation and thus allow us to retrieve information on the circulation from measured mixing ratio distributions. One mechanism is the interplay between the chemical destruction of trace gases and advection. Without advection, chemical sinks would remove those gases which have their sources at Earth's surface completely from the stratosphere, and the fact that - in the long run, and putting weak long-term trends aside - we observe approximately stationary trace gas distributions can only be explained by horizontal and/or vertical advection. Roughly speaking, with the assumption of a chemically stationary atmosphere in force, i.e., when mixing ratio distributions are assumed not to change with time, at each point of the atmosphere the loss by chemical decomposition is compensated for by advection of the related species. That is to say, if a molecule is destroyed, another molecule of this species must be brought to this point by transport if the stationarity condition shall be satisfied. This defines a circulation field corresponding to an equilibrium with respect to atmospheric composition. Mixing ratios changing with time can be understood as a perturbation of this equilibrium assumption, but the task could be conceived of as finding the equilibrium circulation where transport balances 
decomposition. Needless to say, this requires the modeling of sinks in the forward model that is used to predict the atmospheric state. In the current version of ANCISTRUS, the sinks of $\mathrm{CCl}_{4}, \mathrm{CFC}-11, \mathrm{CFC}-12, \mathrm{CH}_{4}, \mathrm{CO}, \mathrm{HCFC}-22, \mathrm{H}_{2} \mathrm{O}$, and $\mathrm{N}_{2} \mathrm{O}$ are taken into account as described in $\mathrm{vC19}$, while, due to its long stratospheric lifetime, $\mathrm{SF}_{6}$ is regarded as inert in the given analysis range. For $\mathrm{CO}$ and $\mathrm{H}_{2} \mathrm{O}$ source reactions are also considered. For reasons discussed above, ANCISTRUS is sensitive only to the decomposition of gases within the diagnosed latitude and altitude range but not to depletion at higher altitudes. Any depletion of, say, $\mathrm{SF}_{6}$ on its way through the mesosphere before it subsides again into the stratosphere thus does not affect the ANCISTRUS results.

The other mechanism by which trace gas distributions convey information on the circulation is the transport of structures. If, say, the maximum of the mixing ratio of a certain gas is at a certain location one day and $5^{\circ}$ further south a month later, this is best explained by a southward velocity of $5^{\circ}$ per month, assuming that this solution satisfies the continuity equation globally. The amplitude of the structures transported is affected by the sinks discussed above. A widely used method that uses this information pathway is the analysis of the ascent rate in the tropical pipe by means of the water vapor tape recorder (Mote et al., 1996).

As opposed to both these simplified views where information pathways are assessed in isolation, both mechanisms contribute to the full picture. ANCISTRUS thus exploits both information pathways. In order to test the sensitivity of ANCISTRUS with respect to each of them, the following tests were performed: as a reference, we use a regular ANCISTRUS result based on zonal mean MIPAS measurements of all nine trace gases from March to April 2005 (Fig. 1a) and for September to October 2010 (Fig. 2a). The choice of these years has no particular reason; the seasonal behavior of these years is well representative of that of the other years available. The months March-April and September-October were chosen because the velocity fields are more structured than at other times of the year and thus more interesting for test purposes.

The circulation fields roughly match our expectations of a typical middle atmospheric meridional circulation. We see mesospheric and upper-stratospheric subsidence in local autumn. The mesospheric pole-to-pole circulation is more pronounced in September-October 2010 than in March-April 2005. Poleward transport in the lower and middle stratosphere is associated with the Brewer-Dobson circulation. Northern polar upwelling in March-April 2005 is particularly interesting: this is explained by the displacement of the polar vortex off the pole during the sudden stratospheric warming taking place at this time, which means that at the pole strongly subsided vortex air is replaced by less subsided air, resulting in a local (Eulerian) upwelling in a $2 \mathrm{D}$ perspective. Due to symmetry around the pole, in a 2D representation there is no horizontal velocity which could reproduce this phenomenon. This result, seeming counterintuitive at first glance, is not a weakness of the ANCISTRUS method but rather a characteristic of the representation of the $3 \mathrm{D}$ atmosphere in $2 \mathrm{D}$ in general.

While the scientific interpretation of these fields of effective velocity is provided elsewhere (e.g., vC19), we are, within the framework of this technical study, not so much interested in the explanation of the atmospheric features but in the sensitivity of the inversion with respect to changes in the setup. Figures $1 \mathrm{~b}$ and $2 \mathrm{~b}$ show the respective $\mathrm{AN}$ CISTRUS run without the consideration of chemical sinks. The structures and circulation patterns described before are still present, but the velocities have changed in a quantitative sense. An additional feature of equatorward transport at about $55 \mathrm{~km}$ altitude, $30^{\circ} \mathrm{S}$ emerged in March-April 2005. As expected, the relevance of sinks is largest at higher altitudes, but in general it is moderate in the sense that minor inaccuracies in sink strengths are not likely to perturb the general picture of the circulation.

By feeding ANCISTRUS with identical trace gas fields for the beginning and the end of the time interval under consideration, the equilibrium circulation was inferred, where sinks are completely balanced by advection (Figs. 1c, d and 2c, d). We performed two variants of this test.

In the first variant, ANCISTRUS was fed with the actual trace gas measurements for the first month and with the same distribution for the second month. The goal was to emulate steady-state conditions and to remove all information contained in the transport of mixing ratio patterns. Here the general picture changes dramatically. Several features of the reference case are not seen anymore. These include the strong subsidence over the South Pole, the response to the stratospheric warming over the North Pole, and poleward transport below $20 \mathrm{~km}$ in both hemispheres, in March-April 2005 (Fig. 1c). The tropical upwelling reaches up into the mesosphere. For September-October 2010 the pole-to-pole circulation is no longer present (Fig. 2c). Two fairly symmetric circulation cells with maximum poleward effective velocities at $50-60 \mathrm{~km}$ dominate the velocity field. Again, the tropical upwelling reaches up into the mesosphere.

Since, strictly speaking, monthly mean mixing ratios do not represent a genuine steady state but rather a snapshot of a transient state, we have repeated this test using annual mean mixing ratio distributions. Without information on monthly changes in the atmospheric state and no seasonal information on the mixing ratio distribution, the inferred circulation is fairly symmetrical, regardless of sinks being estimated with lifetimes typical for March-April (Fig. 1d) or SeptemberOctober (Fig. 2d). With this setup, the tropical upwelling again reaches up into the mesosphere, and the remaining patterns are two rather symmetric transport cells in each hemisphere, the stronger one around $50 \mathrm{~km}$ covering all hemispheric latitudes and a weaker one around $25 \mathrm{~km}$, located in the subtropics. In summary, it is evident that both sources of information contribute to the resulting circulation field, and 

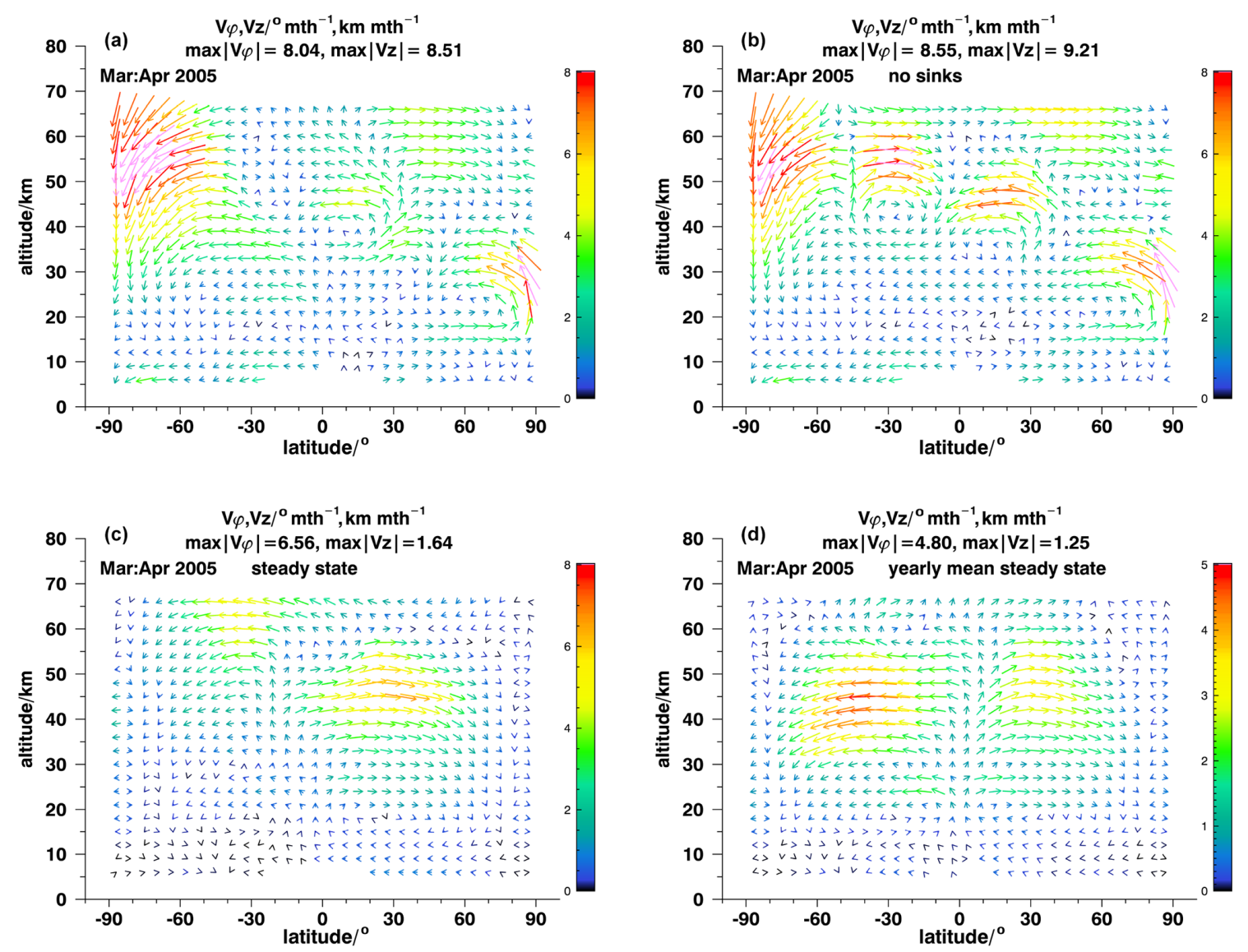

Figure 1. The meridional middle atmospheric circulation as retrieved with ANCISTRUS for March-April 2005 under realistic assumptions (a), without consideration of sinks of trace gases (b), and for sinks perfectly balanced by transport for actual (c) and annual mean (d) conditions. The color scales refer to $\sqrt{\left.\left(v_{\phi} \text { degree }^{-1} \text { month }\right)^{2}+v_{\mathrm{Z}} \mathrm{km}^{-1} \text { month }\right)^{2}}$ for $v_{\phi}$ and $v_{\mathrm{Z}}$ in units of degree per month and kilometer per month. Pink arrows refer to velocities higher than representable by the color scale chosen.

it is necessary to exploit both of them to infer a realistic circulation field.

\section{Model recovery tests}

vCG16 have presented two series of tests. In a first step, they tested the implementation of the transport scheme used. Tests were chosen intentionally simple in order to make it possible to judge whether the algorithm does what it is supposed to, without involving the need of a separate model. If a structure, e.g., a mixing ratio maximum, is transported northward by $5^{\circ}$ in one month when the assumed uniform velocity field is $5^{\circ}$ per month, the success of the test can be directly judged. Diffusive and dispersive characteristics can be tested by analysis of the size of the transported maximum and side wiggles created during the transport. Neither an indication of any malfunction nor otherwise conspicuous features were found in a long series of these forward model tests of which a small subset was shown in vCG16. This kind of test is regarded as severe in the sense of Mayo (1996) because the probability that a flawed transport scheme would be detected is large. Thus, the likelihood that a model which passes these tests is flawed is small. Despite their simplicity, these tests are also general because the operations of the transport scheme are the same everywhere in the analysis space. We thus consider the transport scheme used by ANCISTRUS as valid.

vCG16's second series of tests focused on the inversion scheme. Tests fully based on trace gas real measurements suffer from the fact that the corresponding true velocity fields are not known, and it is thus not clear what the resulting effective velocity fields should be compared to. Model recovery tests based on assumed velocity fields used as surrogate truth along with simulated measurements avoid this problem. Such a test is organized as follows. The assumed velocity field is taken as a reference field and is applied to a measured initial atmospheric state. The resulting solution of the forward transport problem renders the simulated state at a later time. Then the measured initial and the simulated later atmospheric state are fed into the inversion scheme as surrogate measurements, and the resulting velocity field, re- 

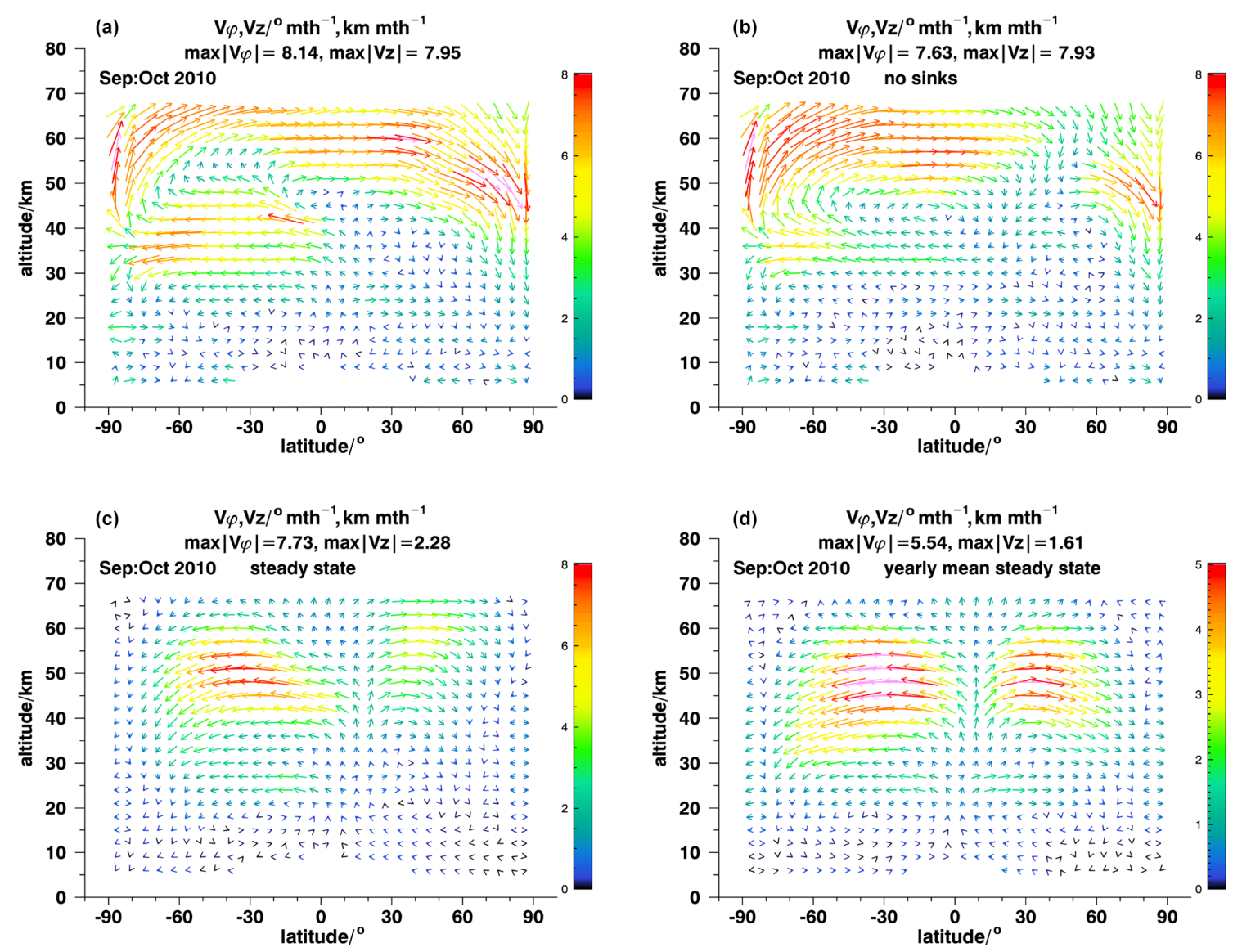

Figure 2. The meridional middle atmospheric circulation as retrieved with ANCISTRUS for September-October 2010 under realistic assumptions (a), without consideration of sinks of trace gases (b), and for sinks perfectly balanced by transport for actual (c) and annual mean (d) conditions. For details, see Fig. 1.

covered without using any information on the surrogate truth, is compared to that reference field used to simulate the later atmospheric state.

For these tests, a sensible choice of the assumed velocity field is essential. Related tests by vCG16 were based on an ad hoc choice of the velocity field. Again, the broad functionality of the inversion scheme could be demonstrated, but a closer look revealed that these tests were only partially successful. The cause of the problems encountered was that the velocity fields used for testing were not solutions of the continuity equation. An inversion scheme that is based on the hard-wired constraint that the results must comply with continuity cannot reproduce velocity fields which were chosen in an ad hoc manner and are not compliant with continuity. Thus, spurious test results at the boundaries of the analysis field did not come unexpectedly and could not refute the validity of the algorithm.

More severe tests must thus use a velocity field that satisfies the continuity equation. On the face of it, tracer and velocity fields from a chemistry-climate model or a chemistrytransport model would serve the purpose. The comparison of ANCISTRUS results with those from such a model, however, suffers from the fact that $2 \mathrm{D}$ velocities cannot be unambiguously compared to 3D model results because there is some room for interpretation of the $2 \mathrm{D}$ effective velocities. The latter include contributions from eddy transport and eddy mixing (see appendices in vCG16 and vC19). Furthermore, there exist some more technical problems: often the zonal mean mixing ratio fields from the climate model deviate in a sizable way from the MIPAS profile. In this case it is not clear what uncertainties shall be assigned to these mixing ratios from the model. Any rescaling of the assumed error variances would substantially change the weights of the measurements in the inversion, and the results would no longer be representative of the application of ANCISTRUS to MIPAS zonal means. Beyond this, modeled trace gas fields are often less structured than the measured ones. The absence of prominent structures, however, means the absence of some useful information for ANCISTRUS, again leading to results not directly comparable to the application of ANCISTRUS measurements to MIPAS trace gas fields. 
The use of velocities from a model applied to MIPAS volume mixing ratios to generate mixing ratio fields at the second time step does not solve the problem either. The reason is this. As we have learned from the tests in Sect. 2, the velocities and the initial mixing ratio distributions cannot be chosen independently. For species with sinks in the stratosphere, it is not only the mixing ratio differences between the beginning and the end of a time step that depend on the velocities, but also the absolute concentrations and their spatial distributions. Inconsistencies between the velocity field and the mixing ratio distributions would thus lead to artifacts in the result of the test. A test where it is not possible to decide if any discrepancy between the reference velocity field and the retrieved velocity field is due to this type of artifact or to a possible malfunction of ANCISTRUS is not useful for validation purposes.

Our way out is to use ANCISTRUS-generated effective velocity fields to simulate trace gas and density fields, apply ANCISTRUS to them, and test the resulting velocity field by comparison to the initial velocity field. The ANCISTRUSgenerated effective velocity fields satisfy the continuity equation. One might argue that this type of model recovery test is circular, but the circularity is related only to the forward transport model, which has already been tested independently. Further, this test of the inversion scheme takes place fully in a two-dimensional world and thus avoids any complication by the interpretation of $2 \mathrm{D}$ effective velocities and their relation to 3D model results.

Results of our model recovery tests are shown in Fig. 3 for March-April 2005 (a, c, e) and for February-March 2010 (b, d, f) and in Fig. 4 for August-September 2010 (a, c, e) and September-October 2010 (b, d, f). Figures 5 and 6 with their reduced altitude range permit a closer look at the lower stratosphere. Panels a and $b$ of the figures show the reference fields of effective velocity, panels $\mathrm{c}$ and $\mathrm{d}$ show the recovered fields, and the respective differences are shown in the panels e and f. The usual diagnostics were applied, and in none of the cases were any peculiarities detected. This provides evidence that the system of equations solved has an unambiguous solution.

For the March-April 2005 case (Figs. 3a, c, e and 5a, c, e), ANCISTRUS reproduces all the patterns of the reference case: subsidence of mesospheric air into the stratosphere at Antarctic latitudes, stratospheric effective upwelling over the North Pole, the bifurcation of an upwelling circulation segment at $30^{\circ} \mathrm{N}, 45 \mathrm{~km}$ altitude, and poleward transport in the southern hemispheric subtropics at $25 \mathrm{~km}$ altitude and in the northern hemispheric subpolar region at $15 \mathrm{~km}$ altitude. All these features are recovered at the correct altitudes and latitudes. At Antarctic latitudes around $55 \mathrm{~km}$ altitude effective velocities are underestimated by $8 \%-9 \%$, while they are over-estimated at $40^{\circ} \mathrm{S}, 40 \mathrm{~km}$, by up to $20 \%$. The center of the circulation structure at tropical latitudes at around $45 \mathrm{~km}$ is shifted downward by $3 \mathrm{~km}$. The largest relative deviations are found where the reference case contains circu- lation segments in opposite directions at adjacent altitudes. The Tikhonov regularization chosen is designed to keep velocity differences between adjacent model grid points small. Thus, this kind of smoothing error observed where the inversion cannot fully resolve the reference field does not come unexpectedly. Also the structures of the slow circulation patterns in the tropopause region and the lower stratosphere are recovered well (Fig 5a, c, e). Effective poleward velocities at 6 and $9 \mathrm{~km}$ altitude and the northward effective velocities in northern midlatitudes at 15 and $18 \mathrm{~km}$ are underestimated in some places.

For the February-March 2010 test case, the situation is very similar to the one discussed above (Figs. 3b, d, f and 5b, d, f). Again, we see southern polar subsidence and the bifurcation of the upwelling circulation segment at $30^{\circ} \mathrm{N}, 45 \mathrm{~km}$ altitude. Contrary to March-April 2005, we see subsidence also over the North Pole, which is an expected phenomenon in polar winter vortices. All major circulation patterns are recovered at the correct latitudes and altitudes. Peak velocities in the mesospheric branches of the circulation are underestimated by about $25 \%$, but in large parts of the analysis domain the inversion is successful also in quantitative terms, particularly below $40 \mathrm{~km}$. Again, the largest discrepancies are found where opposite circulation directions are found at adjacent grid points: due to the smoothing regularization, the inversion does not resolve the small circulation feature at $20^{\circ} \mathrm{S}, 45 \mathrm{~km}$ altitude. A more detailed view on the lower altitudes (Fig $5 b, d, f)$ shows that the branches of the Brewer-Dobson circulation are recovered well $\left(20-40^{\circ} \mathrm{S}\right.$ at 21-27 km altitude and in northern midlatitudes at altitudes between 18 and $27 \mathrm{~km}$ ). The latitudes, altitudes, and velocity values of maximum poleward transport agree well. Also the position, altitude, and strength of tropical upwelling are almost perfectly recovered.

Tests for August-September 2010 and SeptemberOctober 2010 (Figs. 4 and 6) confirm the findings of the first two tests. All patterns and structures are recovered at the correct latitudes and altitudes. For August-September 2010, this refers to the bifurcation of upward and downward effective velocities in the southern polar upper stratosphere near $40 \mathrm{~km}$; the huge area of large southward velocities at 33 $60 \mathrm{~km}$ altitude between equatorial latitudes and about $70^{\circ} \mathrm{S}$; the local maxima of southward effective velocities at 24 $27 \mathrm{~km}$ at about $10^{\circ} \mathrm{S}$ and at $6-9 \mathrm{~km}$ at southern midlatitudes; and the position of the upwelling within the tropical pipe around $10^{\circ} \mathrm{N}$, a large area of high northward velocities peaking between 54 and $60 \mathrm{~km}$ in northern midlatitudes and feeding into northern polar subsidence. Peak velocities are underestimated by about $20 \%$. Quantitative deviations between the reconstructed field and the reference field are largest where velocity gradients are largest. For example, the bifurcation of tropical upwelling velocities between 40 and $50 \mathrm{~km}$ is not well resolved, due to the smoothing characteristic of the regularization. 

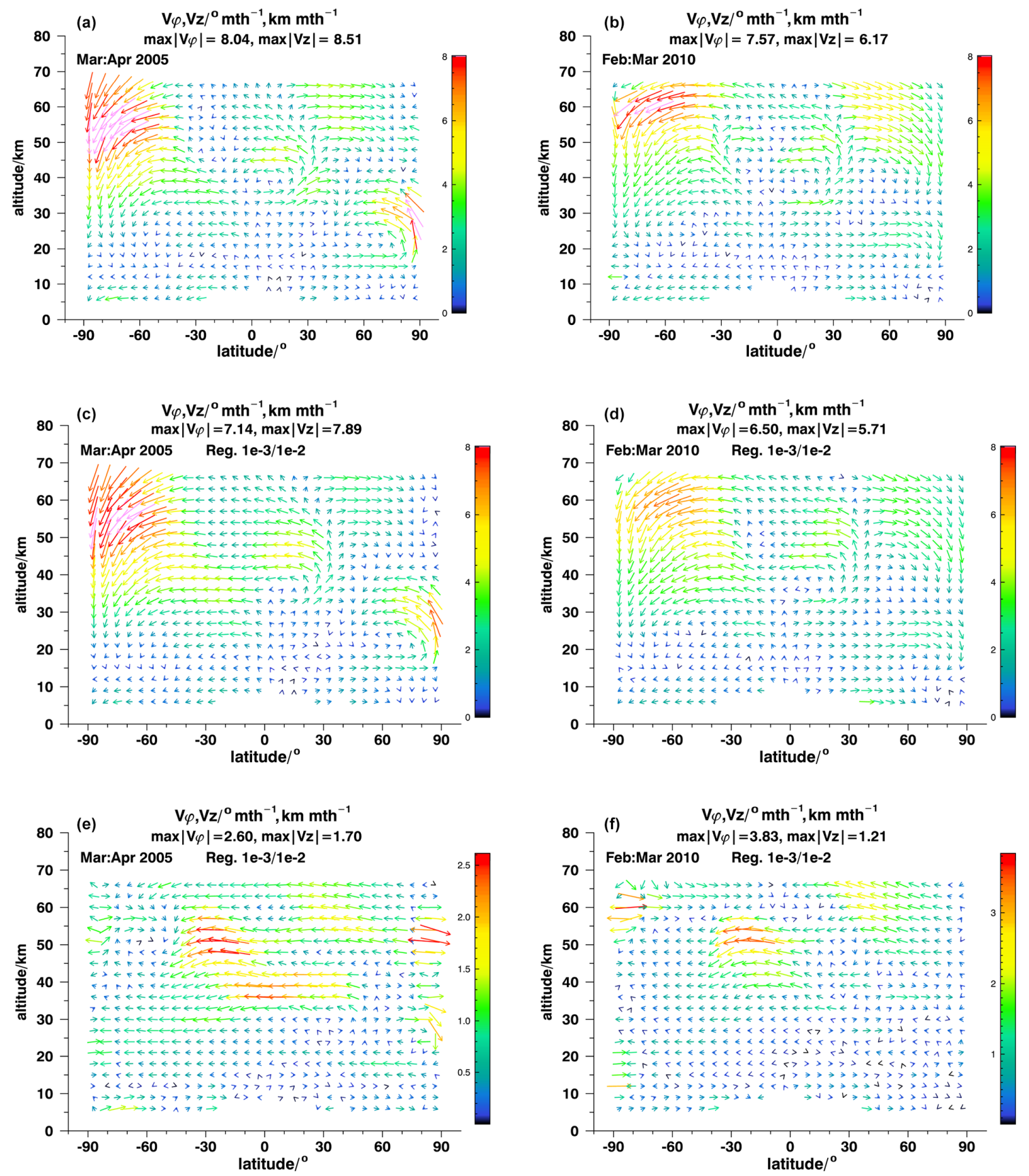

Figure 3. Model recovery tests for March-April, 2005 (a, c, e) and February March, 2010 (b, d, f), reference fields (a, b), results (c, d), and differences $(\mathbf{e}, \mathbf{f})$. Note the different color scales of the difference plots. For details, see Fig. 1.

The September-October 2010 circulation (Figs. 4b, d, f and $6 \mathrm{~b}, \mathrm{~d}, \mathrm{f}$ ) is characterized by a strong northward mesospheric pole-to-pole circulation which is connected to southward transport between 30 and $50 \mathrm{~km}$ in the entire Southern Hemisphere. The general structure of this circulation system and the positions of peak velocities are almost perfectly recovered, but peak velocities are underestimated by about $20 \%$, again due to the smoothing regularization. Poleward velocities at 6 and $9 \mathrm{~km}$ in southern midlatitudes, $21-27 \mathrm{~km}$ between 20 and $60^{\circ} \mathrm{N}$, and equatorward velocities at $15 \mathrm{~km}$ altitude in midlatitudinal and polar northern latitudes are all recovered.

Most importantly, in none of the tests has the inversion scheme created artificial patterns which were not present in the reference case. No major pattern was removed. The small-scale circulation feature at $20^{\circ} \mathrm{S}, 45 \mathrm{~km}$ altitude in February-March 2010 (Fig. 3b, d, f) is the only instance of a feature in the reference field which has not been reproduced. 

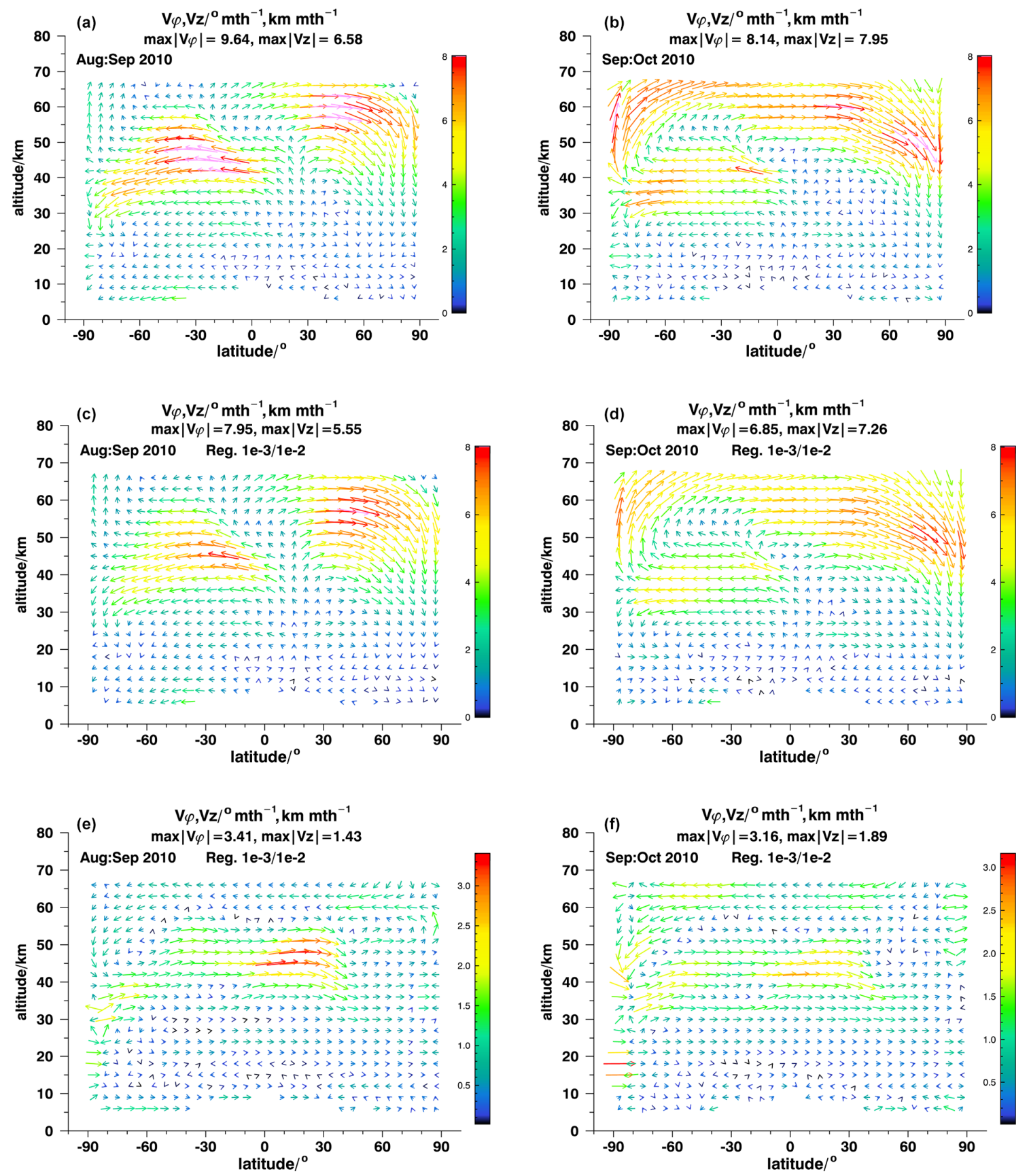

Figure 4. Model recovery tests for August-September 2010 (a, c, e) and September-October 2010 (b, d, f). For details, see Fig. 3.

\section{The role of the regularization strength}

In the previous section, the fact that large velocities are not fully recovered is attributed to the regularization of the inversion. ANCISTRUS uses a Tikhonov (1963)-type regularization which leads to the following object function being minimized:

$\left(\boldsymbol{x}-\boldsymbol{F}\left(\boldsymbol{q} ; \boldsymbol{x}_{0}\right)\right)^{T} \mathbf{S}_{\mathrm{r}}^{-1}\left(\boldsymbol{x}-\boldsymbol{F}\left(\boldsymbol{q} ; \boldsymbol{x}_{0}\right)\right)+\boldsymbol{q}^{T} \mathbf{L}_{1}^{T} \boldsymbol{\Gamma} \mathbf{L}_{1} \boldsymbol{q}$.
$\left(\boldsymbol{x}-\boldsymbol{F}\left(\boldsymbol{q} ; \boldsymbol{x}_{0}\right)\right)$ is the residual between the measured field $\boldsymbol{x}$ of atmospheric state variables and those predicted using the initial field $\boldsymbol{x}_{0}$ and an assumed field of velocities $\boldsymbol{q}$. All these fields are expressed as vectors of length $m$. $\mathbf{S}_{\mathrm{r}}$ is the $m \times m$ covariance matrix characterizing the uncertainties of the residual, under consideration of uncertainties of $\boldsymbol{x}$ and $\boldsymbol{x}_{0} . \mathbf{L}_{1}^{T} \boldsymbol{\Gamma} \mathbf{L}_{1}$ is the $n \times n$ regularization term, where $\mathbf{L}_{1}$ is a first-order difference matrix of dimension $(n-1 \times n)$, expressing the vertical and horizontal differences of adjacent values of horizontal and vertical velocities. These velocities are represented by 

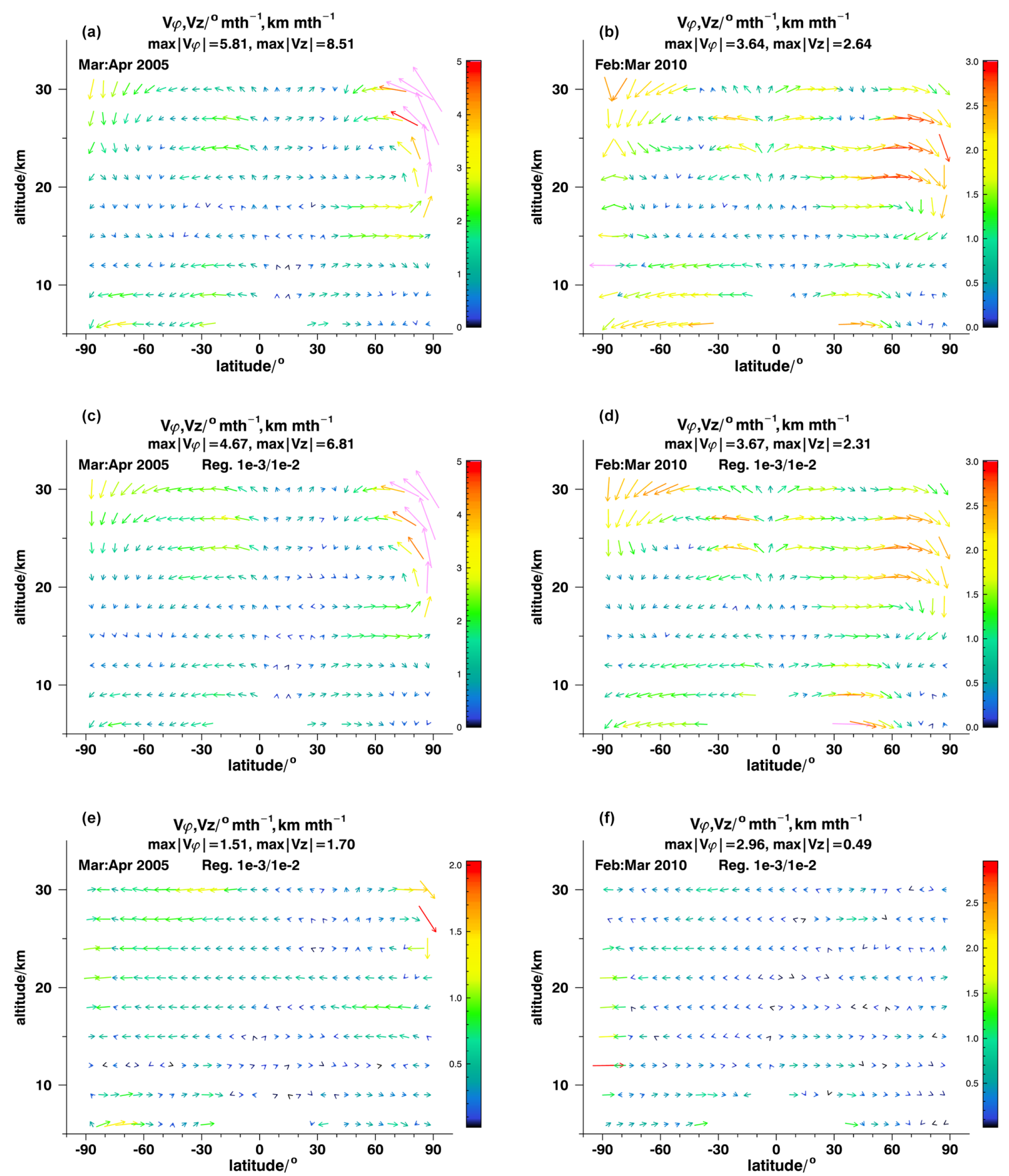

Figure 5. As for Fig. 3 but with a reduced altitude range for clearer representation of lower altitudes.

the $n$-dimensional vector $\boldsymbol{q} . \boldsymbol{\Gamma}$ is a diagonal $(n-1) \times(n-1)$ matrix and controls the strength of the regularization and balances the units. The purpose of the regularization term is to prevent horizontal or vertical gradients of horizontal and vertical velocities from becoming unreasonably large, a typical characteristic of instable, oscillating solutions of ill-posed inverse problems. It goes without saying that the choice of the entries of $\boldsymbol{\Gamma}$ directly affects the solution. Thus it is in order to test how sensitive the resulting velocity fields are on the choice of $\boldsymbol{\Gamma}$. We use September-October 2010 as a test case because the large velocity contrasts are a particular challenge for a Tikhonov-type smoothing regularization.

For September-October 2010, the model recovery test presented in the previous section relied on regularization strengths of $\left(c_{1} \times 1.0 \times 10^{-3}\right)^{2}$ for all entries of $\boldsymbol{\Gamma}$ operating on horizontal velocities and $\left(c_{2} \times 1.0 \times 10^{-2}\right)^{2}$ for those operating on vertical velocities. $c_{1}$ and $c_{2}$ were $6.0 \times 10^{4}$ and $1.0 \times 10^{6} \mathrm{~m}^{-1} \mathrm{~s}$, respectively. In ad- 

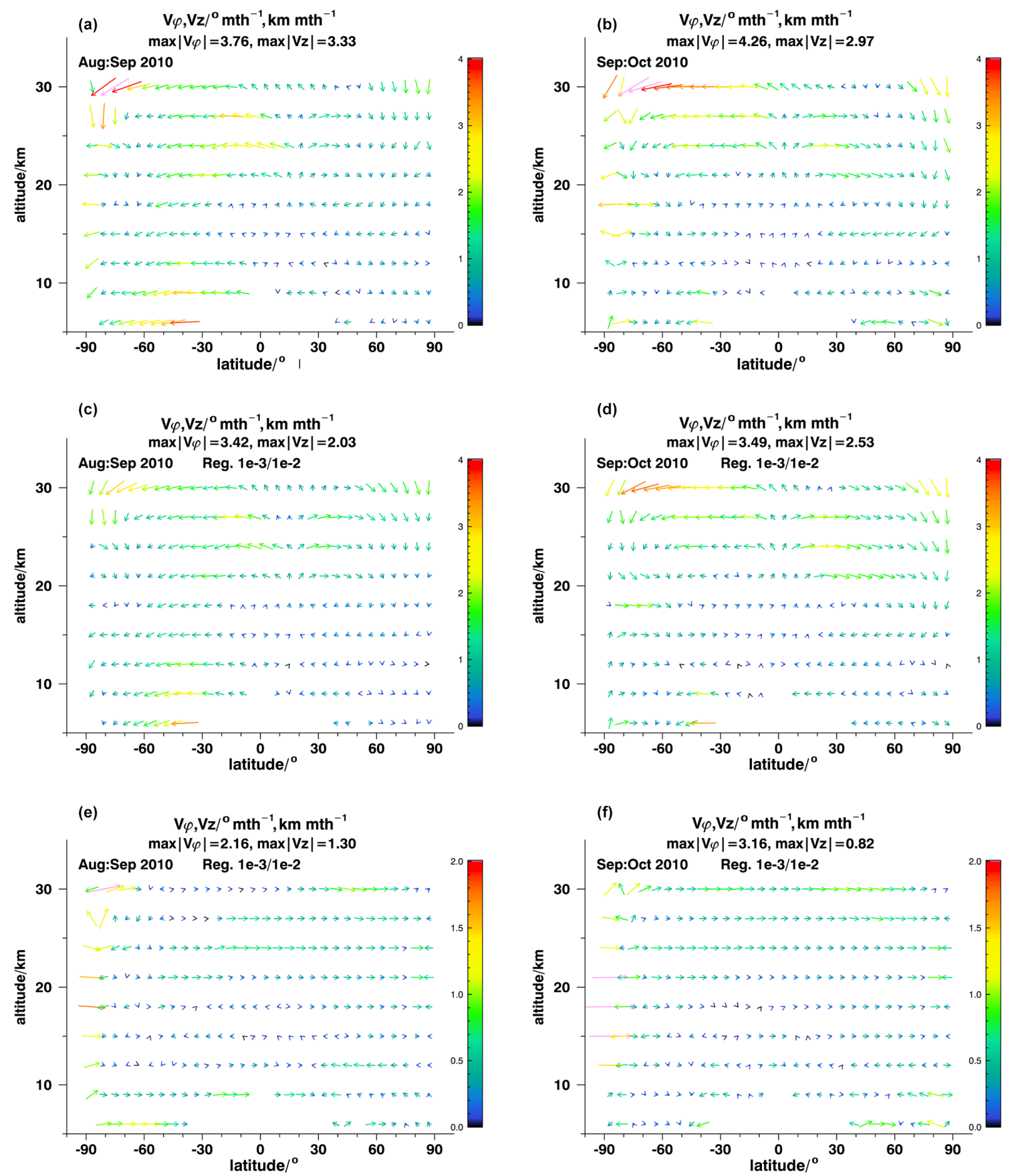

Figure 6. As for Fig. 4 but with a reduced altitude range for clearer representation of lower altitudes.

dition, the following pairs of regularization strengths were tested: $\left(\left(c_{1} \times 5 \times 10^{-3}\right)^{2} ;\left(c_{2} \times 5.0 \times 10^{-2}\right)^{2}\right)$, $\left(\left(c_{1} \times 1 \times 10^{-2}\right)^{2} ;\left(c_{2} \times 1.0 \times 10^{-1}\right)^{2}\right)$, $\left(\left(c_{1} \times 5 \times 10^{-4}\right)^{2} ;\left(c_{2} \times 5.0 \times 10^{-3}\right)^{2}\right), \quad$ and $\left(\left(c_{1} \times 3 \times 10^{-4}\right)^{2} ;\left(c_{2} \times 3.0 \times 10^{-3}\right)^{2}\right)$. Results are presented in Fig. 7.

For the two strongest regularizations the main circulation is qualitatively reproduced but velocities are underestimated by a factor of 2 to 3 . Details of the field are not well resolved
(Fig. 7c, e). With regularization strengths $\left(c_{1} \times 1.0 \times 10^{-3}\right.$; $c_{2} \times 1.0 \times 10^{-2}$ ), which is the one usually applied, all patterns are well resolved, and approximate quantitative agreement is found almost everywhere, except for the peak velocities, which are underestimated by several tens of percent (Fig. 7b). With regularization strengths of $\left(c_{1} \times 5.0 \times 10^{-4}\right.$; $c_{2} \times 5 \times 10^{-3}$ ) the agreement is even better, but there are a significant number of cases for other months where no convergence of the iterative inversion could be obtained 

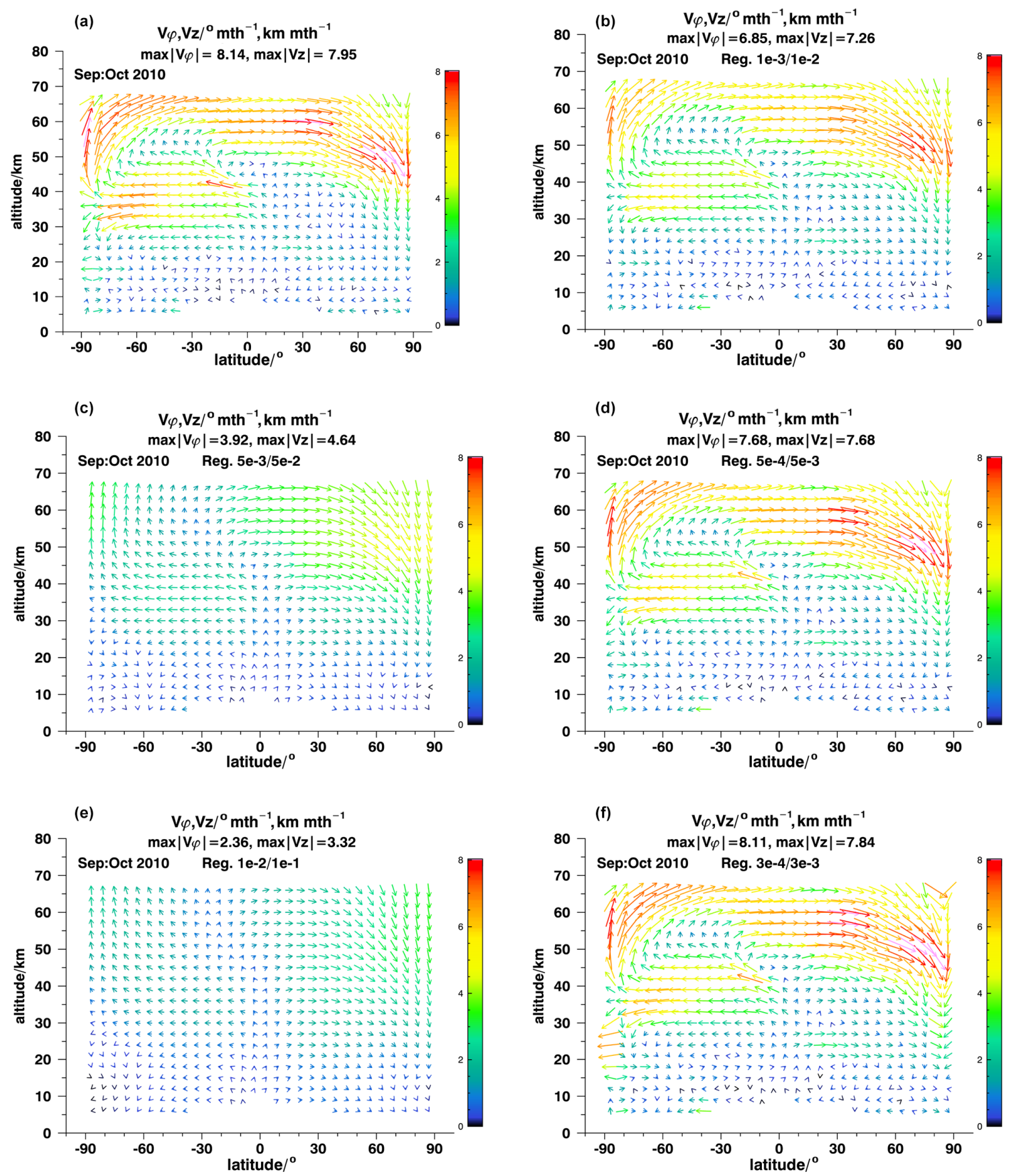

Figure 7. Resulting fields of effective velocity for different regularization strengths. Panel (a) shows the reference velocity distribution and panel (b) the model recovery test for the nominal regularization strength of $\left(c_{1} \times 1.0 \times 10^{-3}\right)^{2}$ for horizontal velocities and $\left(c_{2} \times 1.0 \times 10^{-2}\right)^{2}$ for vertical velocities. Panels $(\mathbf{c})$ and (e) show results for stronger regularization of $\left(\left(c_{1} \times 5.0 \times 10^{-3}\right)^{2} ;\left(c_{2} \times 5.0 \times 10^{-2}\right)^{2}\right)$ and $\left(\left(c_{1} \times 1.0 \times\right.\right.$ $\left.\left.10^{-2}\right)^{2} ;\left(c_{2} \times 1.0 \times 10^{-1}\right)^{2}\right)$, respectively. Panels (d) and (f) show results for weaker regularization of $\left(\left(c_{1} \times 5.0 \times 10^{-4}\right)^{2} ;\left(c_{2} \times 5.0 \times 10^{-3}\right)^{2}\right)$ and $\left(\left(c_{1} \times 3.0 \times 10^{-4}\right)^{2} ;\left(c_{2} \times 3.0 \times 10^{-3}\right)^{2}\right)$, respectively.

(Fig. 7d). An even weaker regularization of $\left(c_{1} \times 3.0 \times 10^{-4}\right.$; $c_{2} \times 3.0 \times 10^{-3}$ ) gives room to some instabilities at the boundaries of the domain, particularly at the South Pole between 15 and $30 \mathrm{~km}$ altitude (Fig. 7f). Thus, we consider the nominal regularization strengths as adequate for routine process- ing. The damping of peak velocities is the price to pay for a robust inversion. With rare cases of non-convergence, good data coverage can be achieved, structures and patterns can safely be recovered, and outside the regions of peak velocities the results are robust even in a quantitative sense. The 
optimal choice of the regularization strength, however, is application-dependent, and for particular case studies, where convergence turns out not to be a problem, a weaker regularization may be more adequate.

\section{Sensitivity tests}

For several reasons, ANCISTRUS results are expected to depend on the selection of species used. First, species with different concentration profiles carry information on the circulation at different altitudes. Thus, omitting, e.g., $\mathrm{CO}$ and $\mathrm{CH}_{4}$ and using only species with sizable concentrations in the lower stratosphere, like $\mathrm{CCl}_{4}$ or $\mathrm{CFC}-11$, will lead to heavily degraded results in the mesosphere. Second, the more species we have in general, the weaker the effect of regularization will be and thus more information can be retrieved, even if the additional information does not change the result in any appreciable manner. Thus, the sensitivity of results with respect to the omission of single species is worth testing. A low sensitivity to the omission of a single species shows the robustness of the methodology.

The corresponding test was set up as follows: first, an ANCISTRUS run was performed for a complete set of species. Then, a series of ANCISTRUS runs was performed, each with one gas omitted, similar to a jackknife method. The difference in velocities caused by the omission of a candidate species is a measure of the sensitivity of the retrieval to this species. These tests were performed for March-April 2005 (left panels of the relevant figures) and September-October 2010 (right panels of the relevant figures) for the omission of CFC-11, CFC-12, and HCFC-22 (Fig. 8), $\mathrm{CCl}_{4}, \mathrm{SF}_{6}$, and $\mathrm{H}_{2} \mathrm{O}$ (Fig. 9), as well as $\mathrm{N}_{2} \mathrm{O}, \mathrm{CH}_{4}$, and $\mathrm{CO}$ (Fig. 10). CFC-11, CFC-12, and HCFC-22 contribute most in the polar spring stratosphere, where gradients between regions of old air depleted in these species and young air rich in these species are large (Fig. 8). Since mixing ratios of these species are low in the upper stratosphere and above, these species contribute most information below about $40 \mathrm{~km}$. Particularly, CFC-11 contains considerable information on meridional effective velocities in tropical and midlatitudinal regions near $30 \mathrm{~km}$ in March-April 2005 (Fig. 8a). Its omission changes these velocities by $20 \%-30 \%$. In contrast, in the region of apparent updraft in northern polar regions, its influence is only about $10 \%$. The sensitivity of horizontal velocities near $30 \mathrm{~km}$ to CFC-11 is confirmed by the September-October 2010 test case.

The effect of the omission of CFC-12 is generally much smaller than of CFC-11 (Fig. 8c, d). This does not necessarily mean that this species carries less information but that its information is more consistent with that of the other species. For the analysis of the major warming event in the northern polar region in March-April 2005 (Fig. 8c), CFC-12 is, in contrast to CFC-11, more relevant for the inference of vertical than horizontal effective velocities. The same is true for
HCFC-22 (Fig. 8f). In this particular test case, HCFC-22 is particularly important at altitudes from $6-12 \mathrm{~km}$ on southern midlatitudes.

$\mathrm{CCl}_{4}$ and $\mathrm{SF}_{6}$ broadly contribute in the same regions as the species discussed before, but their contributions are generally smaller because measurement uncertainties are larger for these species and their weight in the inversion is thus lower (Fig. 9a-d). Except for polar winter conditions, the meridional effective velocities seem to be more sensitive to the omission of these species than the vertical effective velocities. Both in March-April 2005 and September-October 2010, $\mathrm{CCl}_{4}$ contributions are largest to horizontal velocities in the altitude regions of 21-30 km and 6-9 km (Fig. 9a, b). The contributions of $\mathrm{SF}_{6}$ are even smaller than that of $\mathrm{CCl}_{4}$. They exceed $10 \%$ only in the shearing region at $21 \mathrm{~km}$ altitude, $70-80^{\circ} \mathrm{N}$ in March-April 2005 and between 6 and $15 \mathrm{~km}$ altitude in southern midlatitudinal and tropical latitudes in September-October 2010.

$\mathrm{H}_{2} \mathrm{O}$ provides a considerable amount of information (Fig. 9e, f; note the different color scale due to the large amplitude of values). Its contributions are largest where its gradients are largest, namely in the upper troposphere or lower stratosphere and in the mesosphere. In the subsiding segment of the mesospheric circulation at southern polar latitudes in March-April 2005 its contribution exceeds $50 \%$ in some places. In September-October 2010, when the subsiding segment of the mesospheric circulation is situated at northern polar latitudes, the contribution of $\mathrm{H}_{2} \mathrm{O}$ even reaches $100 \%$. $\mathrm{H}_{2} \mathrm{O}$ also provides important information at tropical and midlatitudinal latitudes below $25 \mathrm{~km}$.

$\mathrm{N}_{2} \mathrm{O}$ contributes considerably in the entire altitude range (Fig. 10a, b; note the large range of values represented by the color scale). In wide parts of the atmosphere its contribution exceeds 50\%, particularly in March-April 2005.

$\mathrm{CH}_{4}$ and $\mathrm{CO}$ provide the bulk of information on the circulation in the upper stratosphere and mesosphere (Fig. 10c-f). There, contributions exceed $50 \%$ in wide regions. However, similar to $\mathrm{N}_{2} \mathrm{O}$, they do also provide a lot of information at lower altitudes, which can hardly be appreciated due to the large range of values represented by the color scales of the figures.

Overall, the effects of omission of certain species are generally minor to moderate and confined to specific regions, except for the upper stratosphere and mesosphere, where only a few species carry information, viz., $\mathrm{H}_{2} \mathrm{O}, \mathrm{N}_{2} \mathrm{O}, \mathrm{CH}_{4}$, and $\mathrm{CO}$. The robustness of the inversion with respect to the omission of single species up to about $40 \mathrm{~km}$ indicates that either the MIPAS mixing ratio fields are not biased or that ANCISTRUS is not overly sensitive to such biases. Since a major amount of information exploited by ANCISTRUS is not contained in the mixing ratios themselves but in the mixing ratio differences, biases, if existing, tend to cancel out.

One might argue that the inclusion of species which contribute only little information, such as $\mathrm{SF}_{6}$ or $\mathrm{CCl}_{4}$, is useless. Admittedly the information provided by these species 

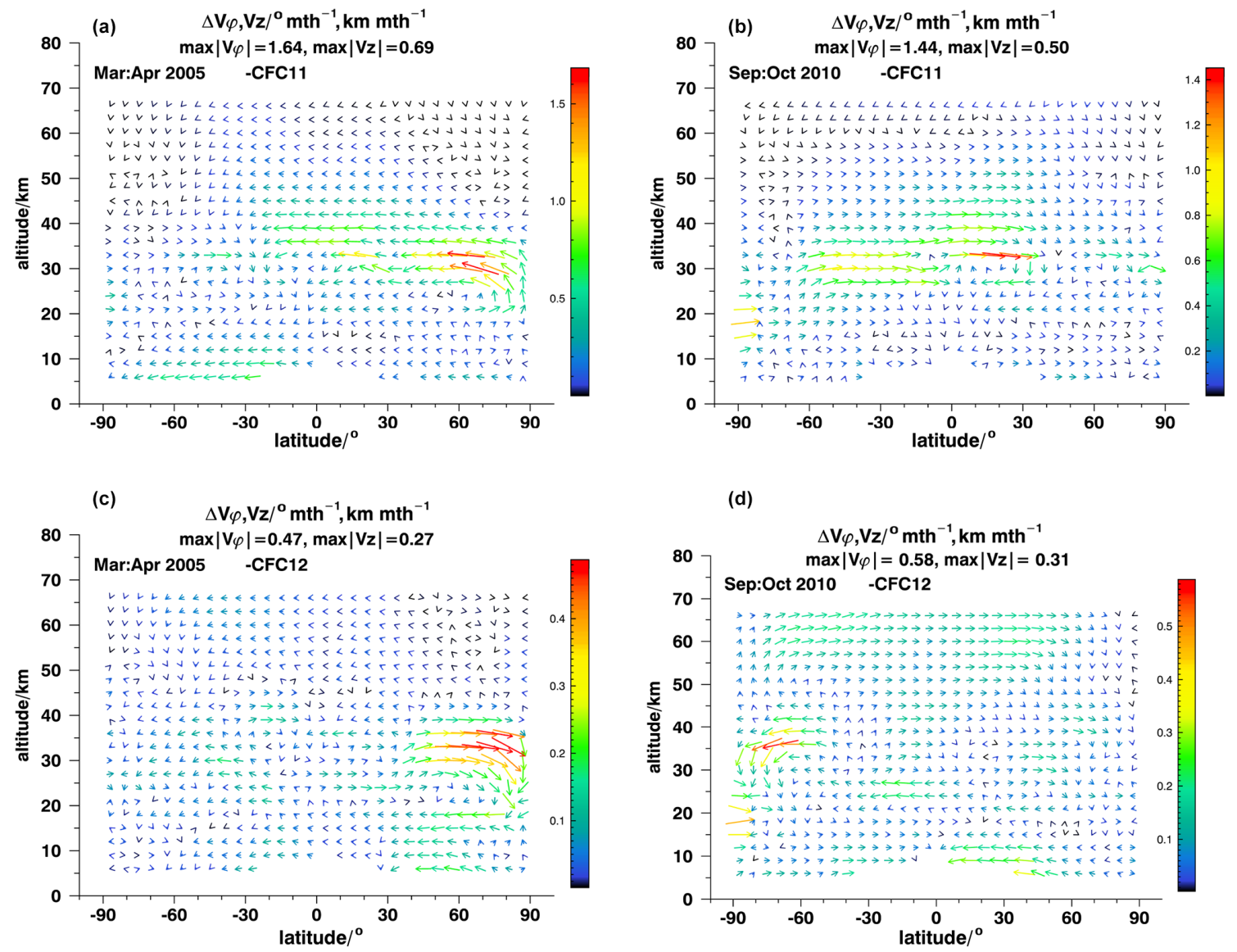

(d)
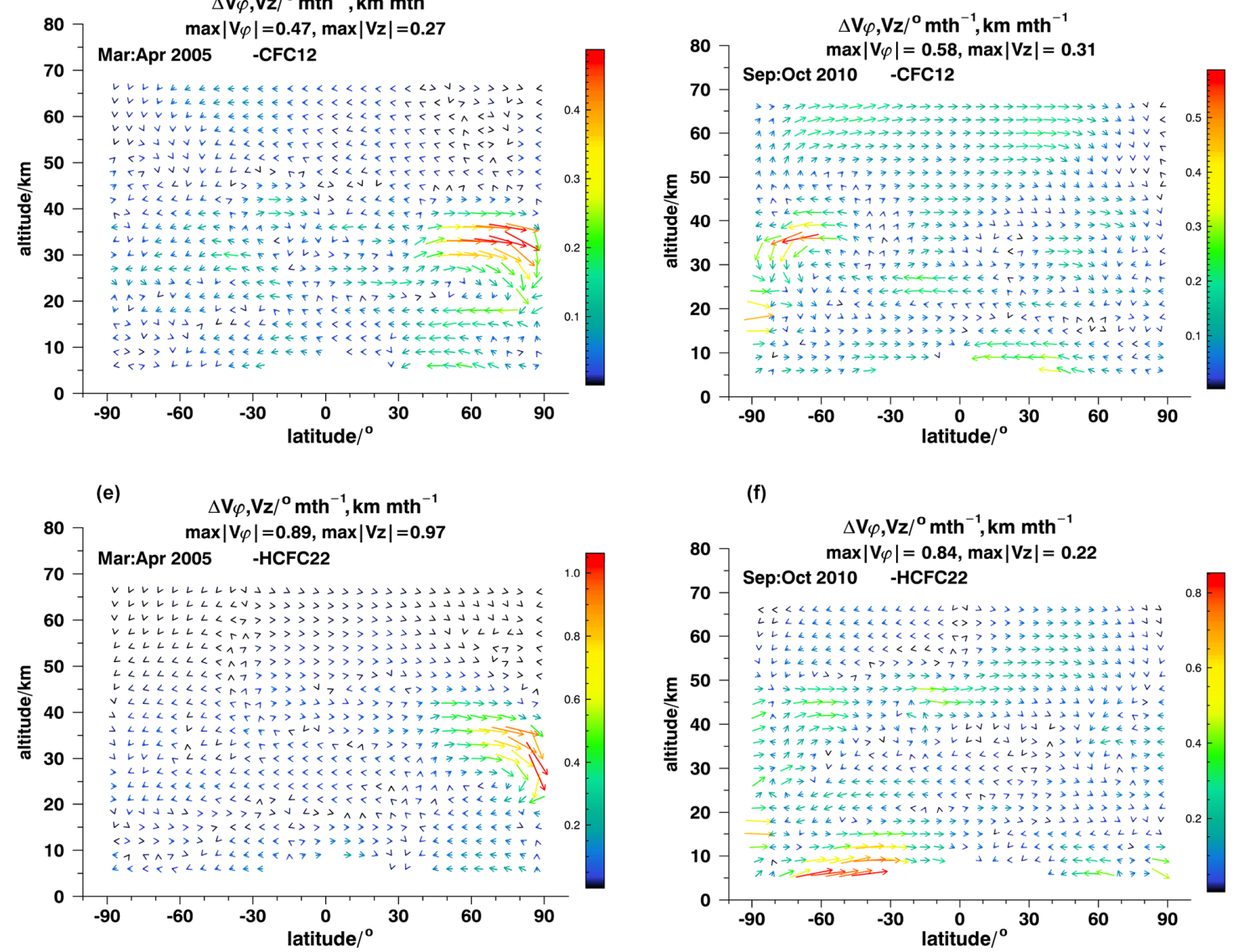

Figure 8. Differences between ANCISTRUS runs with one species omitted and all nine species included for March-April 2005 (a, c, e) and September-October 2010 (b, d, f). The missing species are CFC-11 (a, b), CFC-12 (c, d), and HCFC-22 (e, f).

does not change the results very much. However, the inclusion of these species reduces the estimated uncertainty of the retrieved effective velocities. Figure 11 shows the estimated standard deviations, representing the uncertainty of the retrieved horizontal (panels a, c, e) and vertical (panels b, d, f) velocities due to the propagated uncertainties of the mixing ratio fields, for an ANCISTRUS run with all gases included (panels a, b) and without $\mathrm{CCl}_{4}$ (panels c, d). ${ }^{1}$ The estimated uncertainties are reduced by an appreciable amount, mainly in the lower tropical stratosphere. This is more pronounced for the horizontal than for the vertical velocities. In the tropical middle stratosphere at around $30 \mathrm{~km}$ altitude, the inclu-

\footnotetext{
${ }^{1}$ A similar test, but with an older ANCISTRUS version, has already been performed by Eckert (2018).
} 

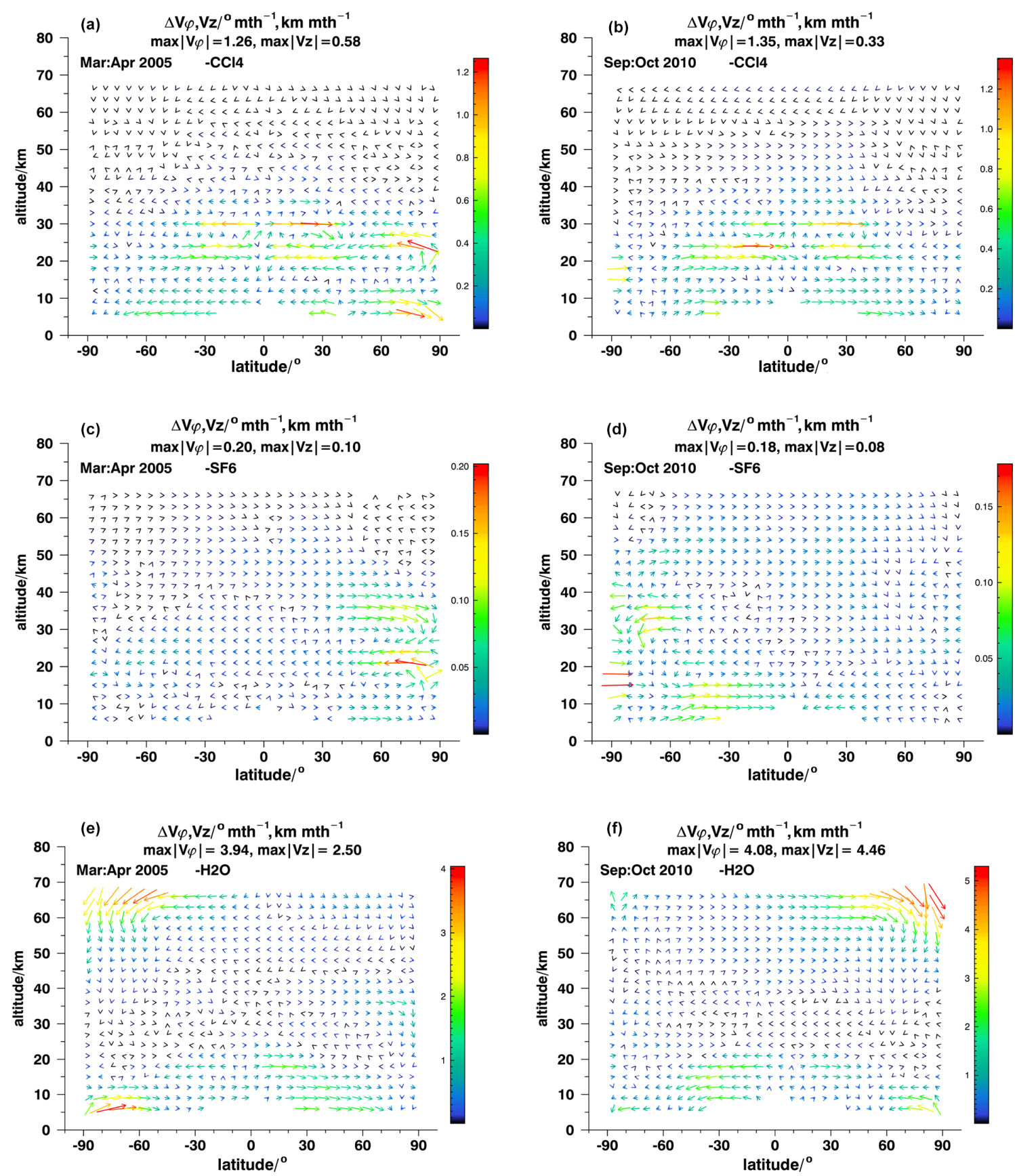

Figure 9. Differences between ANCISTRUS runs with one species omitted and all nine species included for March-April 2005 (a, c, e) and September-October 2010 (b, d, f). The missing species are $\mathrm{CCl}_{4}(\mathbf{a}, \mathbf{b}), \mathrm{SF}_{6}(\mathbf{c}, \mathbf{d})$, and $\mathrm{H}_{2} \mathrm{O}(\mathbf{e}, \mathbf{f})$.

sion of $\mathrm{CCl}_{4}$ increases the altitude region where the standard deviation of $v_{\phi}$ is below $0.06^{\circ}$ per month considerably. For tropical middle-stratospheric vertical velocities the altitude range where standard deviations are below $20 \mathrm{~m}$ per month increases similarly.

The omission of $\mathrm{N}_{2} \mathrm{O}$, chosen as an example of a gas which contributes more information, has a larger impact (Fig. 11e, f). Particularly at altitudes between about 30 and
$50 \mathrm{~km}$, both at polar and tropical latitudes, the standard deviations are up to a factor of 2 higher when $\mathrm{N}_{2} \mathrm{O}$ is omitted.

\section{Conclusions}

ANCISTRUS is a method to infer stratospheric circulation from measured tracer mixing ratios via the inversion of the $2 \mathrm{D}$ continuity equation. The primary area of application of 

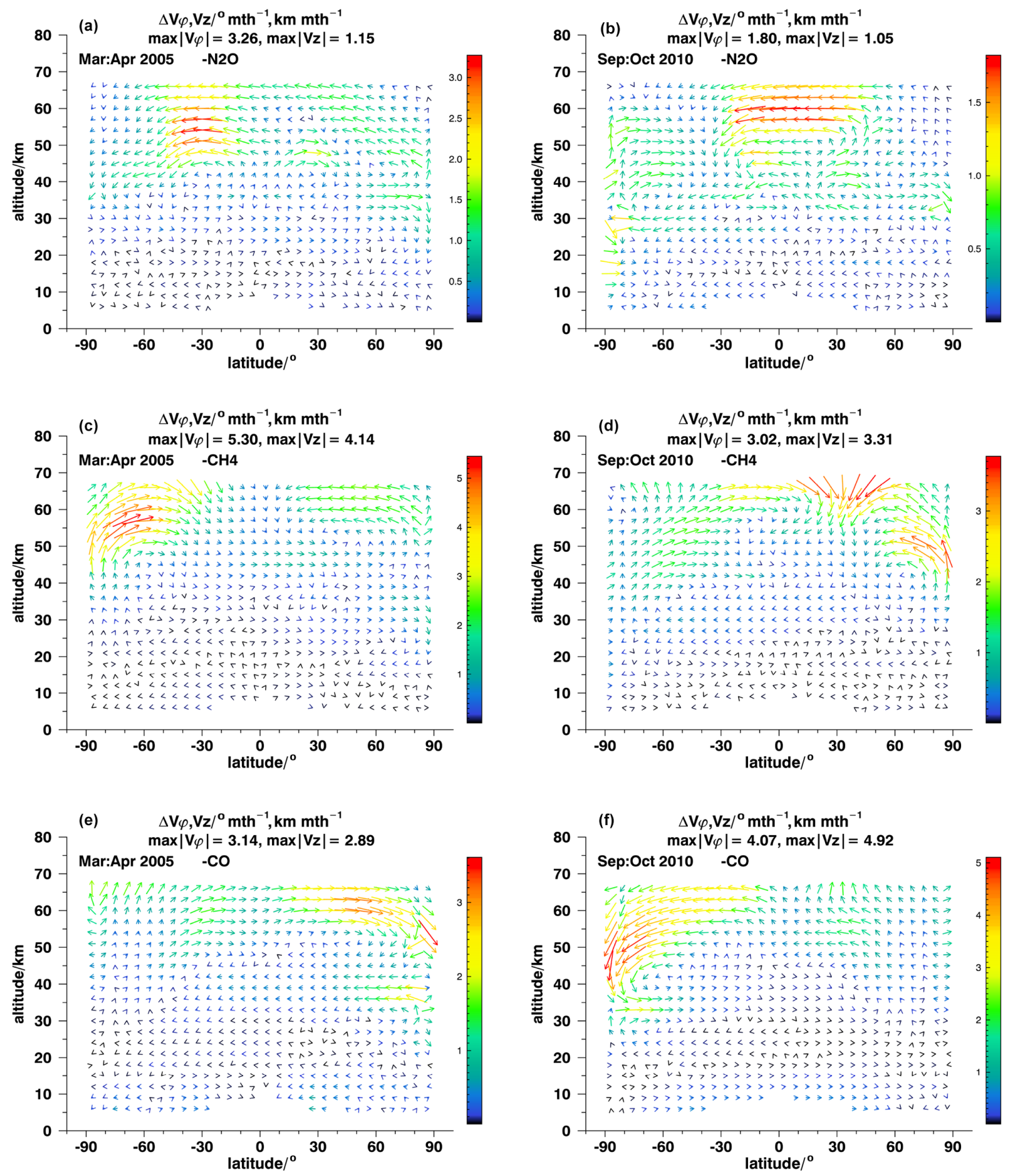

Figure 10. Differences between ANCISTRUS runs with one species omitted and all nine species included for March-April 2005 (a, c, e) and September-October 2010 (b, d, f). The missing species are $\mathrm{N}_{2} \mathrm{O}, \mathrm{CH}_{4}$, and $\mathrm{CO}$.

this method is the investigation into the structure and possible changes in the Brewer-Dobson circulation. In order to validate ANCISTRUS, a series of tests have been performed. By comparison of its application to steady-state conditions to application with deactivated chemical sinks, the contributions of two information pathways were isolated. In the steady state, ANCISTRUS recovers a field of effective velocities which just compensates for the chemical sinks by advection. In contrast, the application with the sinks turned off exclusively exploits the information which is contained in the displacement of patterns of mixing ratios. It was shown that both mechanisms are important to retrieve the full picture and that the latter information pathway is particularly important.

Model recovery tests were performed to test if ANCISTRUS is able to retrieve a known assumed field of ef- 

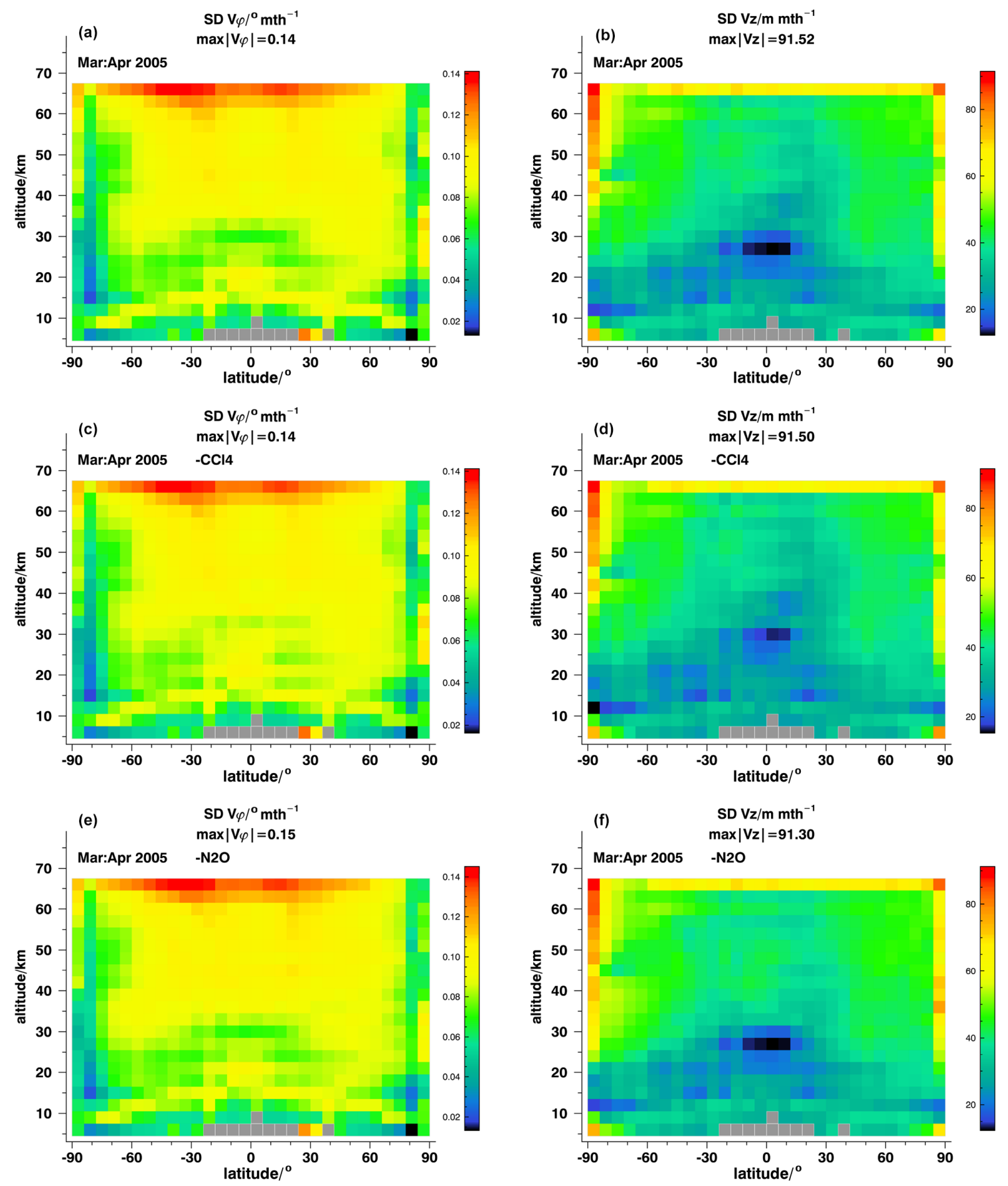

Figure 11. Estimated standard deviations of horizontal $(\mathbf{a}, \mathbf{c}, \mathbf{e})$ and vertical $(\mathbf{b}, \mathbf{d}, \mathbf{f})$ effective velocities for ANCISTRUS runs with all nine gases (a, b), with $\mathrm{CCl}_{4}$ omitted $(\mathbf{c}, \mathbf{d})$ and with $\mathrm{N}_{2} \mathrm{O}$ omitted $(\mathbf{e}, \mathbf{f})$ for March-April 2005.

fective velocities that was used to generate simulated mixing ratio measurements. Up to about $30 \mathrm{~km}$ altitude, ANCISTRUS results have been shown to be fairly accurate in a fully quantitative manner. Above, less measurement information is available, and the peak effective velocities deviate from the reference velocities by up to several tens of percent. Still, structure and patterns are perfectly reproduced and can be regarded as robust. Only patterns of very small scales are not resolved. In no case did ANCISTRUS generate artificial structures not present in the reference data. The prevailing underestimation of peak velocities is attributed to the regularization term in the retrieval equation, which pulls values towards 0 in the case of insufficient measurement information. The choice of the regularization strength in the ANCISTRUS 
version tested here was conservative. A rather strong regularization was chosen to avoid ANCISTRUS producing artificial circulation patterns and to safely achieve convergence of the iteration. According to the terminology of test theory, it had been decided to instead accept type I errors, i.e., to reject a true result, and to safely exclude type II errors, i.e., nonrejection of a false result. The results of this study, however, indicate that there may still be room to fine-tune the regularization in order to achieve less damping of the peak velocities at higher altitudes in a fully quantitative sense. This, however, is deferred to a future paper.

Finally, the information content of the various trace gases used so far in ANCISTRUS applications was investigated. It was found that gases whose omission changes the results only marginally still provide information in the sense that their inclusion reduces the estimated uncertainty of the resulting velocity field. Further, ANCISTRUS proved quite robust with respect to the omission of any single gas. In summary, with respect to the scientific analysis of patterns and structures, we regard the ANCISTRUS algorithm in its current setup as fit for purpose.

Code availability. The ANCISTRUS software, along with the associated software library, is available via the KITOpen depository under ID 1000127728, https://doi.org/10.5445/IR/1000127728 (Grabowski and von Clarmann, 2020).

Data availability. The data used and presented in this paper are available via the KITOpen depository under ID 1000127781, https://doi.org/10.5445/IR/1000127781 (Grabowski et al., 2020).

Author contributions. TvC initiated the study, suggested the test procedures, provided the concept and software to deal with chemical sinks, and wrote the initial draft of the paper. UG performed and visualized the tests and was responsible for the maintenance of the ANCISTRUS software and its further development since its original publication in 2016. Both authors discussed and analyzed the results and worked on the final text of the paper.

Competing interests. Thomas von Clarmann is editor of Atmospheric Chemistry and Physics but has not been involved in the evaluation of this paper. Beyond this, there is no potential conflict of interest.

Acknowledgements. The authors thank Gabriele Stiller for useful comments.

Financial support. The article processing charges for this openaccess publication were covered by a Research Centre of the Helmholtz Association.
Review statement. This paper was edited by Amanda Maycock and reviewed by two anonymous referees.

\section{References}

Andrews, A. E., Boering, K. A., Daube, B. C., Wofsy, S. C., Hintsa, E. J., Weinstock, E. M., and Bui, T. P.: Empirical age spectra for the lower tropical stratosphere from in situ observations of $\mathrm{CO}_{2}$ : Implications for stratospheric transport, J. Geophys. Res., 104, 26581-26595, 1999.

Bernath, P. F., McElroy, C. T., Abrams, M. C., Boone, C. D., Butler, M., Camy-Peyret, C., Carleer, M., Clerbaux, C., Coheur, P.F., Colin, R., DeCola, P., De Mazière, M., Drummond, J. R., Dufour, D., Evans, W. F. J., Fast, H., Fussen, D., Gilbert, K., Jennings, D. E., Llewellyn, E. J., Lowe, R. P., Mahieu, E., McConnell, J. C., McHugh, M., McLeod, S. D., Michaud, R., Midwinter, C., Nassar, R., Nichitiu, F., Nowlan, C., Rinsland, C. P., Rochon, Y. J., Rowlands, N., Semeniuk, K., Simon, P., Skelton, R., Sloan, J. J., Soucy, M.-A., Strong, K., Tremblay, P., Turnbull, D., Walker, K. A., Walkty, I., Wardle, D. A., Wehrle, V., Zander, R., and Zou, J.: Atmospheric Chemistry Experiment (ACE): Mission overview, Geophys. Res. Lett., 32, L15S01, https://doi.org/10.1029/2005GL022386, 2005.

Brewer, A. W.: Evidence for a world circulation provided by measurements of helium and water vapour distribution in the atmosphere, Q. J. Roy. Meteor. Soc., 75, 351-363, 1949.

Dobson, G. M. B.: Origin and distribution of polyatomic molecules in the atmosphere, Proc. R. Soc. A, 236, 187-193, 1956.

Eckert, E.: Changes in Stratospheric Circulation: Evidence and Possible Explanations, $\mathrm{PhD}$ thesis, KIT, Karlsruhe, https://doi.org/10.5445/IR/1000078934, 2018.

Fischer, H., Birk, M., Blom, C., Carli, B., Carlotti, M., von Clarmann, T., Delbouille, L., Dudhia, A., Ehhalt, D., Endemann, M., Flaud, J. M., Gessner, R., Kleinert, A., Koopman, R., Langen, J., López-Puertas, M., Mosner, P., Nett, H., Oelhaf, H., Perron, G., Remedios, J., Ridolfi, M., Stiller, G., and Zander, R.: MIPAS: an instrument for atmospheric and climate research, Atmos. Chem. Phys., 8, 2151-2188, https://doi.org/10.5194/acp-8-21512008, 2008.

Grabowski, U. and von Clarmann, T.: ANCISTRUS software and Processor library, KITopen-ID: 1000127728, https://doi.org/10.5445/IR/1000127728, 2020.

Grabowski, U., Kellmann, S., and Glatthor, N.: Supplement: MIPAS VMR data and circulation fields for publication 10.5194/acp-2020-72, KITopen ID: 1000127781, https://doi.org/10.5445/IR/1000127781, 2020.

Ide, K., Courtier, P., Ghil, M., and Lorenc, A. C.: Unified notation for data assimilation: Operational, sequential and Variational, J. Meteorol. Soc. Jpn., 75, 181-189, 1997.

Mayo, D. G.: Error and the growth of experimental knowledge, The University of Chicago Press, Chicago, USA, 1996.

Mote, P. W., Rosenlof, K. H., McIntyre, M. E., Carr, E. S., Gille, J. C., Holton, J. R., Kinnersley, J. S., Pumphrey, H. C., Russell III, J. M., and Waters, J. W.: An atmospheric tape recorder: The imprint of tropical tropopause temperatures on stratospheric water vapor, J. Geophys. Res., 101, 3989-4006, https://doi.org/10.1029/95JD03422, 1996. 
Ray, E. A., Moore, F. L., Elkins, J. W., Rosenlof, K. H., Laube, J. C., Röckmann, T., Marsh, D. R., and Andrews, A. E.: Quantification of the $\mathrm{SF}_{6}$ lifetime based on mesospheric loss measured in the stratospheric polar vortex, J. Geophys. Res.-Atmos., 122, 46264638, https://doi.org/10.1002/2016JD026198, 2017.

Reddmann, T., Ruhnke, R., and Kouker, W.: Threedimensional model simulations of $\mathrm{SF}_{6}$ with mesospheric chemistry, J. Geophys. Res., 106, 14525-14537, https://doi.org/10.1029/2000JD900700, 2001.

Rodgers, C. D.: Inverse Methods for Atmospheric Sounding: Theory and Practice, vol. 2 of Series on Atmospheric, Oceanic and Planetary Physics, edited by: Taylor, F. W., World Scientific, Singapore, New Jersey, London, Hong Kong, 2000.

Stiller, G. P., von Clarmann, T., Haenel, F., Funke, B., Glatthor, N., Grabowski, U., Kellmann, S., Kiefer, M., Linden, A., Lossow, S., and López-Puertas, M.: Observed temporal evolution of global mean age of stratospheric air for the 2002 to 2010 period, Atmos. Chem. Phys., 12, 3311-3331, https://doi.org/10.5194/acp12-3311-2012, 2012.

Tikhonov, A.: On the solution of incorrectly stated problems and method of regularization, Dokl. Akad. Nauk. SSSR, 151, 501504, 1963.

von Clarmann, T. and Grabowski, U.: Direct inversion of circulation and mixing from tracer measurements - Part 1: Method, Atmos. Chem. Phys., 16, 14563-14584, https://doi.org/10.5194/acp-1614563-2016, 2016. von Clarmann, T., Grabowski, U., Stiller, G. P., Monge-Sanz, B. M., Glatthor, N., and Kellmann, S.: An observation-based climatology of middle atmospheric meridional circulation, Atmos. Chem. Phys. Discuss. [preprint], https://doi.org/10.5194/acp-2019-704, in review, 2019.

Waters, J. W., Froidevaux, L., Harwood, R. S., Jarnot, R. F., Pickett, H. M., Read, W. G., Siegel, P. H., Cofield, R. E., Filipiak, M. J., Flower, D. A., Holden, J. R., Lau, G. K., Livesey, N. J., Manney, G. L., Pumphrey, H. C., Santee, M. L., Wu, D. L., Cuddy, D. T., Lay, R. R., Loo, M. S., Perun, V. S., Schwartz, M. J., Stek, P. C., Thurstans, R. P., Boyles, M. A., Chandra, K. M., Chavez, M. C., Chen, G.-S., Chudasama, B. V., Dodge, R., Fuller, R. A., Girard, M. A., Jiang, J. H., Jiang, Y., Knosp, B. W., LaBelle, R. C., Lam, J. C., Lee, K. A., Miller, D., Oswald, J. E., Patel, N. C., Pukala, D. M., Quintero, O., Scaff, D. M., Van Snyder, W., Tope, M. C., Wagner, P. A., and Walch, M. J.: The Earth Observing System Microwave Limb Sounder (EOS MLS) on the Aura satellite, IEEE Trans. Geosci. Remote, 44, 1075-1092, https://doi.org/10.1109/tgrs.2006.873771, 2006.

Waugh, D. W. and Hall, T. M.: Age of stratospheric air: theory, observations, and models, Rev. Geophys., 40, 1010, https://doi.org/10.1029/2000RG000101, 2002. 